\title{
Cotton Fiber and Carbon Materials Filters for Efficient Wastewater Purification
}

\author{
Natalia Politaeva ${ }^{*}$, Elena Taranovskaya ${ }^{2}$, Liliya Mukhametova ${ }^{3}$, Svetlana Ilyashenko ${ }^{4}$, \\ Irina Atamanyuk ${ }^{5}$, Rafat Al Afif ${ }^{6}$, Christoph Pfeifer ${ }^{6}$ \\ ${ }^{1}$ Peter the Great St. Petersburg Polytechnic University, St. Petersburg, 194021, Russia \\ ${ }^{2}$ Orenburg State University, Orenburg, Russian Federation, 460018 \\ ${ }^{3}$ Kazan State Power Engineering University, Kazan, Krasnoselskaya Street, 5, 1420066, Russia \\ ${ }^{4}$ Plekhanov Russian University of Economics, Moscow, 117997, Russia \\ ${ }^{5}$ Hamburg University of Technology, Hamburg 21073, Germany \\ ${ }^{6}$ University of Natural Resources and Life Sciences, Vienna, Austria
}

\begin{abstract}
Carbon materials and cotton fibers (CFs) are eco-friendly and cost-effective solutions for water purification. However, enhancing the filtration efficiency of these materials remains challenging. In this study, the capacity of heat-treated sorbents (CFs and low-temperature graphite intercalation compounds (LT-GICs)) to improve the efficiency of wastewater purification from heavy metals and petroleum compounds, was investigated. The properties of the thermally modified CFs were studied in order to obtain a material which is highly efficient in purifying wastewater from heavy metal ions (HMIs). The duration of sorption equilibrium and the optimal ratio of heat-treated cotton fibers (HTCFs) and wastewater were determined. The adsorption capacities of CFs for iodine and methylene blue were determined before and after the heat treatment. Experimental results indicated that thermal treatment of CFs resulted in increased numbers of micropores and mesopores, indicating a high sorption capacity for petroleum products (PPs) in wastewater $(A=11.5 \mathrm{~g} / \mathrm{g})$ with an efficiency score of $90 \%$. Furthermore, LT-GIC/CF composite filters were optimized for efficient purification. The results indicated that a filter with a composition of $1 \mathrm{~g}$ LT-GIC $+3 \mathrm{~g}$ CF had the highest sorption capacity for HMIs $(28.7 \mathrm{mg} / \mathrm{g}$ ) and PPs $(80.6 \%)$ due to its looser surface structure. The X-ray phase analysis of the sintered composite filters showed the presence of carbon in the amorphous phase, which had a similar structure to the activated carbon from black coal. In summary, the high sorption capacities and simple preparation processes of LT-GIC/CF composites make them potential candidates for wastewater purification.
\end{abstract}

Keywords: Cotton fibers; Heavy metals; Low-temperature graphite intercalation compounds; Petroleum products; Wastewater purification

\section{Introduction}

Sorption materials for wastewater treatment can be obtained from various production wastes. A vast variety of sorbents are produced from agricultural residues: sunflower husk, barley (Shaikhiev et al., 2010), wheat husk (Sobgaida et al., 2010), tea (Aslan et al., 2016), soybean and mustard (Humelnicu et al., 2015), leaf (Svyatchenko et al., 2020), peels (Kusrini et al., 2018), and others (Desmiarti et al., 2019; Olufemi and Eniodunm, 2018). The 
raw materials can be subjected to ultrasonic (Nasyrov et al., 2019) and heat treatment and exposed to acids and alkalis, thus obtaining materials with high sorptive properties at minimum costs (De Gisi et al., 2016).

Shaikhiev et al. (2010) demonstrated the possibility of using barley grain shells for removing oil and PPs from water. They showed that the modification of shells using weak solutions of sulfuric acid resulted in the removal of the hydrophilic component from the materials, which decreased water absorption by $16.5 \%$. Consequently, the sorption capacity of these shells for oil and PPs increased by $30 \%$.

The development of inexpensive adsorbents from plant waste to remove $\mathrm{Cu}$ (II) and $\mathrm{Zn}$ (II) ions from WW was studied by Humelnicu et al. (2015). The sorptive properties of soy bran and mustard husk were investigated. The authors examined the influence of the contact time, initial concentration of metal ions, $\mathrm{pH}$, sorbent mass, and temperature on the sorption capacities of sorbent materials. Alslaibi et al. (2014) investigated the use of olive seeds to extract iron, lead, and copper ions. The use of cotton stems and apricot seeds as biosorbents of heavy metals have also been studied (Kahraman et al., 2008; Bhatnagar et al., 2015). These materials were selected for their availability and cellulose structure, which has a high sorption capacity.

Carbon-based sorbents for wastewater treatment are widely used (Perederii et al., 2009). They have high sorption capacities for HMIs and PPs (Nasyrov et al., 2017; Politaeva et al., 2017a, 2017b). Graphene is another promising material that can be employed for these purposes (Rozaini et al., 2019).

A large amount of waste is generated during the production of woven materials. Waste from weaving is stored at factory sites and then taken to landfills, involving considerable costs. Sirotkina and Novoselova (2005) treated waste from the weaving of CFs with oxidized polypropylene. These materials had sorption capacities of up to $30 \mathrm{~g} / \mathrm{g}$ and were able to withstand several cycles of regeneration. The disadvantage of these materials, however, was that they were prone to microbiological degradation.

Shaikhiev (2017) investigated the possibility of using wool processing waste for wastewater purification from PPs. The use of carbon fibers in various textile forms allows the effective sorption and simultaneous filtration of gases and liquids (Mochida and Korai, 2000; Lysenko, 2007). Kharitonov et al. (2016) and Mostovoy and Yakovlev (2019) demonstrated the possibility of improving the properties of composite materials by modifying them with nanotubes (Kharitonov et al., 2016) and graphite-graphene structures (Mostovoy and Yakovlev, 2019). These additives increased the strength and porosity of the materials. Carbon-fullerene structures are highly efficient for the removal of heavy metals and PPs in wastewater treatment (Politaeva et al., 2017a, 2017b; Sobgaida et al., 2008).

Carbon materials, especially CFs, have been suggested as water purification materials due to their eco-friendly properties and cost-effectiveness (Li et al., 2017). However, enhancing the filtration efficiency of these materials remains challenging. In this study, the thermal treatment of the sorbents, CFs and LT-GICs, was investigated as a means of improving the purification efficiency of wastewater from PPs and HMIs.

\section{Methods}

Cotton fiber waste was obtained from a weaving factory in Saratov, Russia. This waste was generated during the weaving of the shoot with the warp yarn. A total of 1.5-2.0 tons of cotton fiber per year are available as waste material on the market with no other utilization route. LT-GICs were obtained by the electrochemical intercalation of sulfuric acid between the layers of extra-pure grade $(C>99.5)$ graphite at the pilot plant, GRAFIT in 
Engels, Russia. The treatment of the LT-GICs at temperatures above $400^{\circ} \mathrm{C}$ gives rise to thermally expanded graphite with high specific surface areas and sorption capacities.

To evaluate the purification efficiency, model solutions containing HMIs (zinc, cadmium, lead, and copper), which were prepared from the sulfates of these metals, were used. Model solutions were prepared from weighed portions of salts and the Russian state standard samples of the aforementioned metal sulfates. The residual content of HMIs was determined using a voltammetric analyzer, AKV-07 MK (000 NPP Tomianalit, Tomsk, Russia). To determine the sorption capacity for PPs, real, mechanically treated wastewater from an oil refinery was used. The residual content of PPs in the model solutions was determined using the Crystal 5000 gas chromatograph (ZAO SKB Khromatek, Yoshkar-Ola, Russia).

The heat treatment of CF waste was carried out in the SNOL muffle furnace in a steel cell, which limited the access of oxygen. Thermogravimetric studies of the samples were carried out using the OD-103 derivatograph (MOM, Hungary). Samples weighing $0.2 \mathrm{~g}$ were placed in crucibles made of fused aluminum oxide and heated in air to $1000^{\circ} \mathrm{C}$ at a rate of $10^{\circ} \mathrm{C} / \mathrm{min}$. Calcined alumina was used as a reference sample, and the temperature was recorded using the Pt-Pt/Rh thermocouple. The specific surface area of materials was determined via the Brunauer-Emmett-Teller (BET) technique using the automated sorption unit TriStar II 3020 (Micromeritics, USA).

To determine the sorption capacity for iodine, $20 \mathrm{~g}$ of the adsorbent was boiled for 10 min in $200 \mathrm{~mL}$ of a $0.2 \mathrm{~N}$ hydrochloric acid solution. Then, the sorbent was washed until it produced a negative reaction with chloride ions. The thoroughness of the washing process was verified with a $10 \%$ solution of silver nitrate. After washing, the sorbent was dried at $110^{\circ} \mathrm{C}$ for $1 \mathrm{~h}$. To determine the sorption capacity, $1 \mathrm{~g}$ of sorbent was shaken for $15-30 \mathrm{~min}$ with $100 \mathrm{~mL}$ of a $0.1 \mathrm{~N}$ iodine solution in potassium iodide $(25 \mathrm{~g} / \mathrm{L})$. After that, a sample of $10 \mathrm{~mL}$ was titrated with a $0.1 \mathrm{~N}$ solution of sodium thiosulfate in the presence of a starch indicator. The iodine number was calculated using Equation 1:

$$
E=\frac{(V 1-V 2) \cdot 12.7}{M}[\mathrm{mg} / \mathrm{L}]
$$

where $V 1$ is the volume of sodium thiosulfate used for titration of the initial sample; $V 2$ is the volume of sodium thiosulfate used for the titration of the sample after treatment with the sorbent; 12.7 is the molecular weight of iodine; and $M$ is the sorbent mass $(0.25 \mathrm{~g})$.

To determine the sorption capacity for methylene blue, $1 \mathrm{~g}$ of the sample was shaken with a $15 \%$ methylene blue solution for $5 \mathrm{~min} .5 \mathrm{~mL}$ of solution was added every $5 \mathrm{~min}$ until the solution ceased to discolor. The sorption capacity was calculated using Equation 2:

$$
\mathrm{E}_{\mathrm{mg}}=5 \mathrm{n}
$$

where $n$ is the volume of the added dye in $\mathrm{mL}$.

The volume of micropores in the adsorbents was measured via the molecular probes technique using a number of liquids with increasing molecular size. For this, the sorbent was saturated with an organic liquid and boiled for $15 \mathrm{~min}$. The suspension was filtered using a Buchner funnel, creating a pressure of $60 \mathrm{~mm} \mathrm{Hg}$. The sample was weighed before and after boiling, and the total pore volume was determined using Equation 3:

$$
V=\frac{m_{1}-m}{m * p}
$$


where $m_{1}$ is the mass of the wet sorbent $(\mathrm{g}) ; m$ is the mass of the dry sorbent $(\mathrm{g})$; and $\rho$ is the density of the organic liquid $\left(\mathrm{g} / \mathrm{cm}^{3}\right)$.

The efficiency of the model for wastewater purification was calculated using the following equation:

$$
E f f=\frac{C i n i-C f i n}{C i n i} * 100 \%
$$

where $C_{\text {ini }}$ and $C_{\text {fin }}$ are the initial and final concentrations of the solution in $\mathrm{mg} / \mathrm{L}$.

The sorption capacity $A_{\mathrm{i}}$ of the adsorbent at any given time was determined using the following equation:

$$
A i=\frac{C o-C t}{m} * V
$$

where $C_{\mathrm{t}}$ is the concentration of the solution at a given time and $m$ is the mass of the sorbent.

Microscopic photographs of the samples were taken using the QUANTA 200 3D scanning electron microscope (Fei, USA).

Sintered composite filters (SCFs) with rigidly bonded, fixed structures were prepared from CFs and LT-GICs. Various ratios of LT-GICs and CFs were used. The filters were produced by mechanical mixing to produce a homogeneous state and enable subsequent sintering of the resulting mixtures in a special steel mold $(5 \mathrm{~cm}$ in diameter and $2 \mathrm{~cm}$ in height). Filters with volumes, $V=39 \mathrm{~mL}$ were obtained (Figure 1). Sintering was performed at $T=450^{\circ} \mathrm{C}$ for $8 \mathrm{~min}$. Based on the pretests, filters of two compositions were prepared and tested:

1) 3 g LT-GIC + 1 g CF (filter no. 1);

2) 1 g LT-GIC + 3 g CF (filter no. 2).

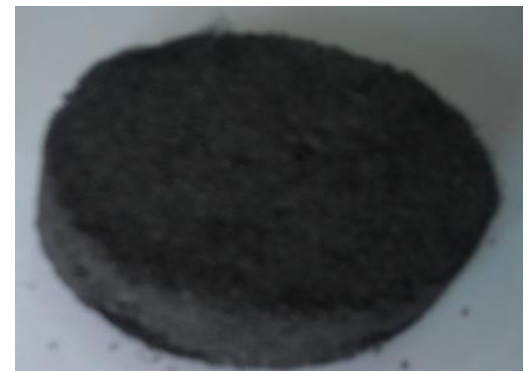

Figure 1 Sintered composite filter made from LT-GICs and CFs (3:1)

X-ray phase analysis of the obtained SCFs was carried out using the POWDIX 600 X-ray powder diffractometer (ADANI, Moscow, Russia).

\section{Results and Discussion}

\subsection{Material Characterization}

Thermogravimetric analysis of $\mathrm{CF}$ showed that the substance transformation occurred in the temperature range of $250-450^{\circ} \mathrm{C}$ (Figure 2). So, the further studies on the optimal temperature and time for heat treatment of waste were carried out within this temperature range. The temperature, $T$ was varied from 200 to $500^{\circ} \mathrm{C}$ (with intervals of $50^{\circ} \mathrm{C}$ ), and the time, $\tau$, from 2 to $10 \mathrm{~min}$ (with intervals of $2 \mathrm{~min}$ ). The appearance (color) of CFs during heat treatment changed from milky white to black. The optimal conditions for $\mathrm{CF}$ processing were selected: $T=450^{\circ} \mathrm{C}$ and $\tau=8 \mathrm{~min}$. Under these conditions, an HTCF that had a high sorption capacity for wastewater purification from HMIs was formed (Table 1). 
The time to reach sorption equilibrium, during which the adsorbent was kept in model solutions, was $30 \mathrm{~min}$, with an optimal ratio of $1 \mathrm{~g}$ of adsorbent per $1 \mathrm{~L}$ of wastewater.

It was found that the efficiency of metal ions for wastewater purification from HMIs decreases in the order $\mathrm{Cu}^{2+}>\mathrm{Zn}^{2+}>\mathrm{Cd}^{2+}>\mathrm{Pb}^{2+}$ (see Table 1). The radii $(\mathrm{r}, \mathrm{nm})$ of these metal ions increase in the same sequence. The smaller the radius of the cation, the easier it is sorbed into the pores of the adsorbent.

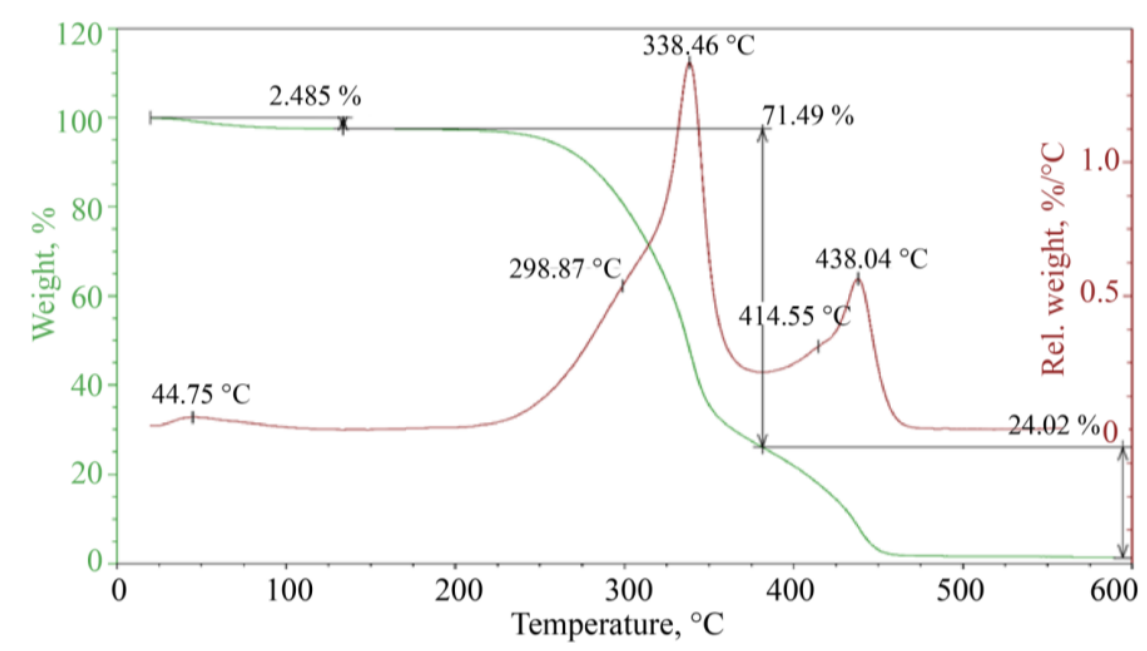

Figure 2 Thermogravimetry and differential thermogravimetry of cotton fiber waste

The purification efficiency calculated using Equation 4 and the sorption capacity calculated using Equation 5 are presented in Table 1.

Table 1 Purification efficiency, Eff and sorption capacity, $A$ for HMI extraction from wastewater using the HTCF sorbent. $C_{\text {ini }}(10 \mathrm{mg} / \mathrm{L})$ and $C_{\text {fin }}$ are the initial and the final concentrations of the solution, $r$ is the radius of metal ion

\begin{tabular}{lcccc}
\hline \multicolumn{1}{c}{ Metal cation } & $C_{\text {fin }}, \mathrm{mg} / \mathrm{L}$ & $E f f, \%$ & $r, \mathrm{~nm}$ & $A, \mathrm{mg} / \mathrm{g}$ \\
\hline Lead (II) & 0.54 & 94.5 & 0.126 & 6.9 \\
Cadmium (II) & 0.39 & 96.0 & 0.099 & 13.2 \\
Zinc (II) & 0.17 & 98.3 & 0.083 & 14.4 \\
Copper (II) & 0.01 & 99.9 & 0.080 & 15.1 \\
\hline
\end{tabular}

The sorption capacity for iodine, determined from Equation 1 (24.1\% for CF, $91.1 \%$ for HTCF) was characterized by the number of micropores with a size of $1.0 \mathrm{~nm}$. After heat treatment, the number of micropores with $d=1.0 \mathrm{~nm}$ increased by a factor of about 3.5. The sorption capacity for methylene blue, calculated from Equation 2, was characterized by the presence of mesopores (1.5-1.7 nm), and was $33 \mathrm{mg} / \mathrm{g}$ for CF, and $185 \mathrm{mg} / \mathrm{g}$ for HTCF. After the heat treatment of $\mathrm{CF}$, its porosity increased and its specific surface area increased significantly. The specific surface area of CF was $S_{\mathrm{sp}}=50.8 \mathrm{~m}^{2} / \mathrm{g}$, and the specific surface area of HTCF was $S_{\mathrm{sp}}=1700 \mathrm{~m}^{2} / \mathrm{g}$ (Table 2). The high specific surface area was due to the formation of defects in the material along the fiber surface and the hollow structure inside the fiber. Thus, a heat treatment is advised.

The distribution of micropores in HTCF and its sorptive characteristics were determined using molecular probes and calculated from Equation 3 (see Table 2). 
Table 2 Sorptive characteristics of CF and HTCF

\begin{tabular}{lccc}
\hline \multicolumn{4}{c}{ Micropore size distribution determined using molecular probes } \\
\hline Characteristics & Pore diameter, $\mathrm{nm}$ & $\begin{array}{r}\text { Pore volume of CF, } \\
\mathrm{cm}^{3} / \mathrm{g}\end{array}$ & $\begin{array}{r}\text { Pore volume of HTCF, } \\
\mathrm{cm}^{3} / \mathrm{g}\end{array}$ \\
\hline Alcohol, $\mathrm{cm}^{3} / \mathrm{g}$ & 0.52 & 3.5 & 4.40 \\
Acetone, $\mathrm{cm}^{3} / \mathrm{g}$ & 0.56 & 2.5 & 2.82 \\
Benzene, $\mathrm{cm}^{3} / \mathrm{g}$ & 0.59 & 3.0 & 3.40 \\
Toluene, $\mathrm{cm}^{3} / \mathrm{g}$ & 0.63 & 2.1 & 2.53 \\
Water, $\mathrm{cm}^{3} / \mathrm{g}$ & 0.50 & 1.0 & 1.40 \\
\hline \multicolumn{4}{c}{ Main characteristics } \\
Sorption capacity for iodine, \% & 24 & 91 \\
Specific surface area $S, \mathrm{~m}^{2} / \mathrm{g}$ & 50.8 & 1700 \\
pH of the aqueous extract & 6.8 & 9.0 \\
Moisture, \% & 5.9 & 0 \\
Efficiency of cleaning from PP, \% & 87 & 90 \\
Sorbent capacity, g/g & 9.8 & 11.5 \\
\hline
\end{tabular}

Along with adsorption, HMI is also extracted through chemisorption processes. Cotton fiber is almost pure cellulose; it is a natural polymer whose elementary links have the chemical formula $\left(-\mathrm{C}_{6} \mathrm{H}_{10} \mathrm{O}_{5}-\right)_{\mathrm{n}}$. A characteristic feature of cellulose is the presence of three functional hydroxyl groups, $\mathrm{OH}^{-}$, in each elementary unit that are capable of interacting with HMIs by replacing hydrogen cations with metal cations according to the scheme:

$$
\mathrm{zROH}+\mathrm{Me}^{\mathrm{z}} \rightarrow(\mathrm{R} \cdot \mathrm{O})_{z} \mathrm{Me}+\mathrm{ZH}^{+}
$$

Analysis of the IR spectra of CF and HTCF (Figure 3) showed that the intensity of the spectrum for hydroxyl groups $\left(3365 \mathrm{~cm}^{-1}\right)$ and asymmetric $\mathrm{CH}_{2}$ groups $\left(2930 \mathrm{~cm}^{-1}\right)$ of HTCF was significantly lower than that for CF without heat treatment, but the spectrum for the formation of carboxylate ions (1400-1600 $\mathrm{cm}^{-1}$ ) increased.

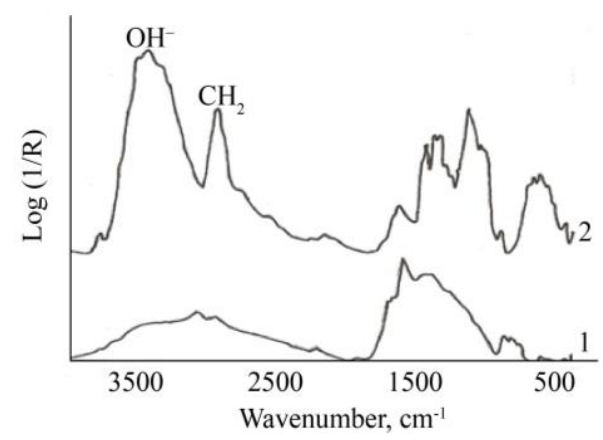

Figure 3 IR spectra: 1-HTCF, 2-CF

Most likely, during heat treatment, hydrogen bonds are broken, hydrogen is removed, and a negative charge is formed on the surface of the sorbent. The negative charge on the surface of the sorbent gives it the properties of a weakly acidic cation exchanger. The extraction of metal cations from water is made possible due to the electrostatic forces of the negatively charged sorbent surface and positively charged HMI. This mechanism can occur according to the following scheme:

$$
z R O^{-}+M e^{z+} \rightarrow(R O)_{z} M e
$$


The assumption that a negative charge is formed on the surface of was also confirmed by the shift of the $\mathrm{pH}$ value of the HTCF water extract to the alkaline region $\left(\mathrm{pH}_{\mathrm{CF}}=6.8\right.$, pHнтсF $=9.0)($ Table 2).

\subsection{Adsorption Tests}

The use of HTCF to extract PPs from real wastewater in an oil refinery in Saratov, Russia was examined. It was established that for $C_{\text {ini_PP }}=20 \mathrm{mg} / \mathrm{L}$, the total sorbent capacity of the material calculated from Equation 5 was $A=11.5 \mathrm{~g} / \mathrm{g}$, and the effluent purification efficiency calculated using Equation 4 was Eff $=90 \%$ (Table 2).

Microstructural studies of HTCF showed that the fibers had a loose surface with partial deformation, which increased their sorption capacity. The individual fibers were intertwined, forming a framework, and the PPs were extracted not only due to adsorption into the pores, but also due to adhesion between the fibers (Figure 4c).

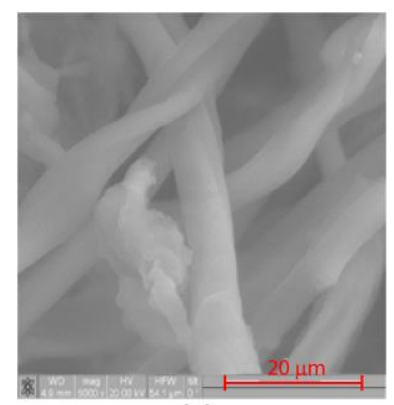

(a)

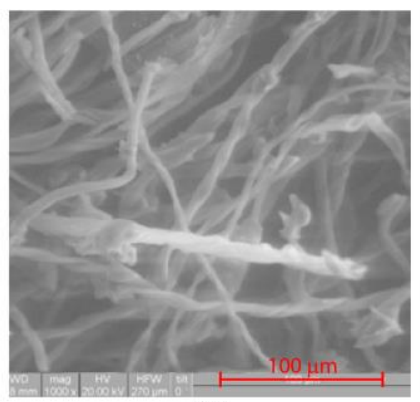

(b)

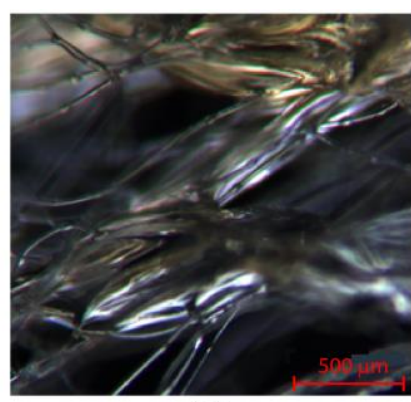

(c)

Figure 4 Microstructure of HTCF: (a) Magnification $\times 500$; (b) Magnification $\times 250$; (c) After adsorption of PP, magnification $\times 500$

An innovative technical solution to produce SCFs with a rigidly connected, fixed structure was developed. The resulting filters retained their shape after filtering $10 \mathrm{~L}$ of wastewater. The results of HMI extraction from wastewater using SCF are shown in Table 3. Both filters no. 1 (21.2 mg/g) and no. $2(28.7 \mathrm{mg} / \mathrm{g})$ showed a high degree of purification. Filter no. 2 showed the highest sorption capacity for HMI. This filter comprised $1 \mathrm{~g}$ of LTGICs and $3 \mathrm{~g}$ of CFs and therefore, provided a looser surface structure.

Table 3 Final concentrations $\left(C_{\mathrm{fin}}\right)$ and wastewater purification efficiencies $(E f f$, \%) of filters of various compositions $\left(C_{\text {ini }}\right.$ of $\left.\mathrm{HMI}=10 \mathrm{mg} / \mathrm{L}\right)$

\begin{tabular}{|c|c|c|c|c|c|c|c|c|}
\hline \multirow{2}{*}{$\begin{array}{c}\text { Filter } \\
\text { no. }\end{array}$} & \multirow[b]{2}{*}{ Filter composition } & \multicolumn{2}{|c|}{$\mathrm{Cd}^{2+}$} & \multicolumn{2}{|c|}{$\mathrm{Pb}^{2+}$} & \multicolumn{2}{|c|}{$\mathrm{Cu}^{2+}$} & \multirow{2}{*}{$\begin{array}{c}A, \\
\mathrm{mg} / \mathrm{g}\end{array}$} \\
\hline & & $\begin{array}{c}C_{\text {fin }}, \\
\mathrm{mg} / \mathrm{L}\end{array}$ & $E f f, \%$ & $\begin{array}{c}C_{\text {fin }}, \\
\mathrm{mg} / \mathrm{L}\end{array}$ & $E f f, \%$ & $C_{\text {fin }}, \mathrm{mg} / \mathrm{L}$ & Eff, $\%$ & \\
\hline 1 & $3 \mathrm{~g}$ LT-GIC $+1 \mathrm{~g} \mathrm{CF}$ & 3.7964 & 62.03 & 3.0321 & 69.67 & 3.6578 & 63.42 & 21.2 \\
\hline 2 & $1 \mathrm{~g} \mathrm{LT}-\mathrm{GIC}+3 \mathrm{~g} \mathrm{CF}$ & 3.6741 & 63.36 & 1.6593 & 83.40 & 3.5300 & 64.47 & 28.7 \\
\hline
\end{tabular}

SCF was used to purify $450 \mathrm{~mL}$ of wastewater from PPs. The initial concentration of PPs was $15 \mathrm{mg} / \mathrm{L}$. The temperature was $22 \pm 2^{\circ} \mathrm{C}$, and the filtration rate was $20 \mathrm{~mL} / \mathrm{min}$. The difference in areas under the chromatograms (Figure 5) was used to determine the final concentration of PPs after purification. The purification efficiencies calculated from the chromatograms is presented in Table 4. 


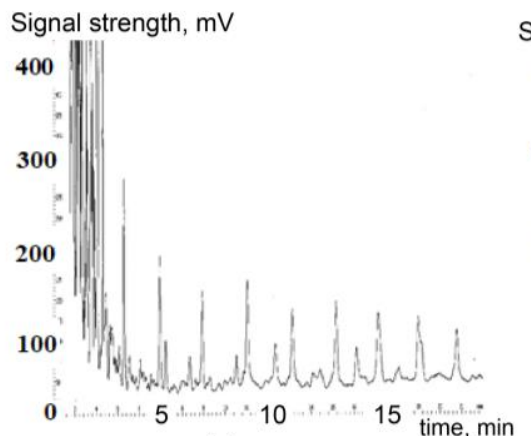

(a)

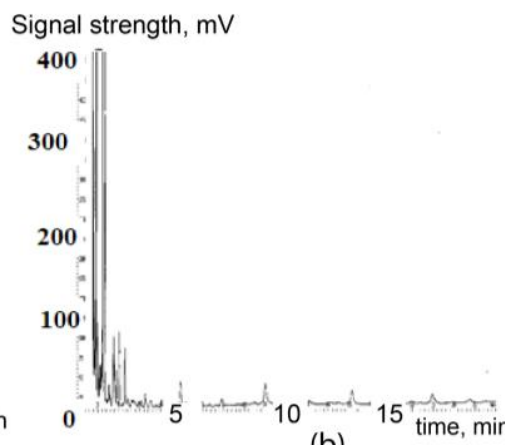

(b)

Figure 5 Chromatograms for determining the content of petroleum products: (a) In wastewater with PP; (b) After PP cleaning with filter no. 2

Table 4 Efficiency of wastewater treatment from petroleum products by SCFs $\left(C_{\text {ini }}=15\right.$ $\mathrm{mg} / \mathrm{L})$

\begin{tabular}{cccc}
\hline Filter no. & Filter composition & $C_{\text {fin }}, \mathrm{mg} / \mathrm{L}$ & Eff, $\%$ \\
\hline 1 & 3 g LT-GIC + 1 g CF & 5.50 & 63.3 \\
2 & 1 g LT-GIC + 3 g CF & 2.91 & 80.6 \\
\hline
\end{tabular}

Tables 3 and 4 show that the efficiency of wastewater treatment from HMIs and PPs depended on the filter's composition. Filter no. 2, composed of LT-GIC:CF (1:3), possessed the highest sorption capacity for HMI and PP. Heat treatment of LT-GIC promoted the expansion of the starting material, and the resulting thermally expanded graphite (TEG) led to the formation of more homogeneous compositions with CF. Simultaneously, the CF thread became thinner and coking of the CF occurred. This resulted in a looser porous structure of the filter and increased its sorption capacity. The developed specific surface area and high porosity of the TEG and the heat-treated CF gave rise to the high adsorptive properties of SCF.

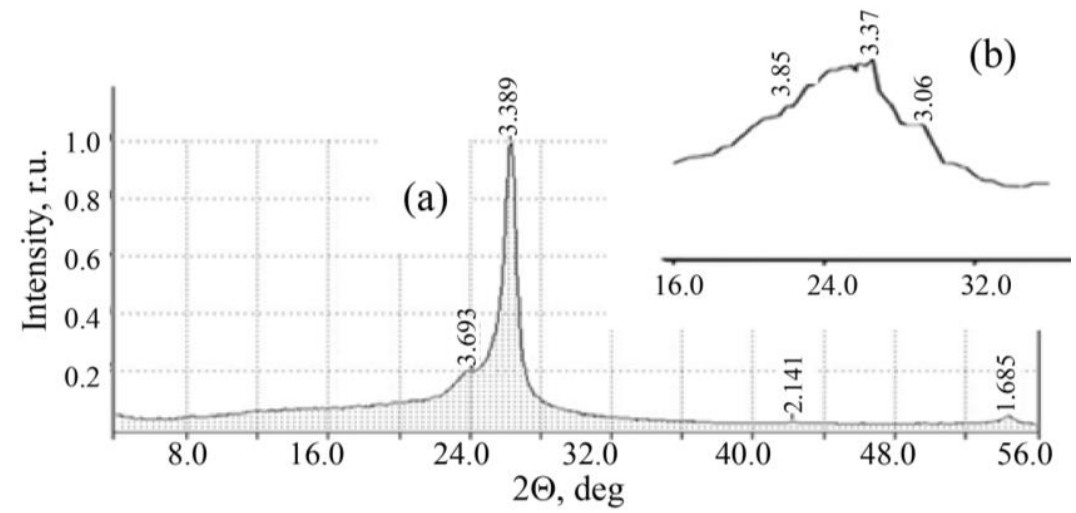

Figure 6 X-ray patterns of: (a) SCF obtained from LT-GIC and CF $(3: 1)$ at $450^{\circ} \mathrm{C}$; (b) KAD activated carbon

The results of the X-ray phase analysis of SCF are presented in Figure 6a. The X-ray diffraction patterns revealed the presence of carbon in the amorphous phase (reflection angle of 3.389). This indicated the formation of surface carbon sorbents and explained the increase in the sorption capacity of SCF after heat treatment of the materials at $T=450^{\circ} \mathrm{C}$. The X-ray diffraction patterns for SCF and activated black coal of the KAD brand (Figure 
$6 \mathrm{~b})$, showed that the reflection angles for these materials were in the same areas. The carbon found on the SCF surface had a similar structure to that of the KAD activated carbon.

\section{Conclusions}

This study investigated filtration materials obtained from a weaving factory. The CFs and the LT-GICs were examined as sorbents for wastewater purification from heavy metals and petroleum compounds. Their chemical and physical properties were studied. SCFs were obtained from two compositions of LT-GIC and CF. The filter comprised of $1 \mathrm{~g}$ LT-GIC $+3 \mathrm{~g}$ CF had the highest sorption capacity for HMIs $(28.7 \mathrm{mg} / \mathrm{g})$ and PPs $(80.6 \%)$, as it had a looser surface structure than the other filter. Future studies will be aimed at examining the ability of the obtained filters to extract various pollutants from wastewater. Comprehensive water purification at real enterprises will be carried out.

\section{Acknowledgements}

Federal Ministry of Education and Research (BMBF) in Germany (031B0403A) and Ministry of Science and Higher Education of the Russian Federation (RFMEF158717X0038 agreement N14.587.21.0038 from 17.07.2017)

\section{References}

Alslaibi, T.M., Abustan, I., Ahmad, M.A., Foul, A.A., 2014. Kinetics and Equilibrium Adsorption of Iron (II), Lead (II), and Copper (II) onto Activated Carbon Prepared from Olive Stone Waste. Desalination and Water Treatment, Volume 52(40-42), pp. 78877897

Aslan, S., Yildiz, S., Ozturk, M., Polat, A., 2016. Adsorption of Heavy Metals onto Waste Tea. European Scientific Journal, Volume 12(10), pp. 269-275

Bhatnagar, A., Sillanpää, M., Witek-Krowiak, A., 2015. Agricultural Waste Peels as Versatile Biomass for Water Purification - A Review. Chemical Engineering Journal, Volume 270, pp. 244-271

De Gisi, S., Lofrano, G., Grassi, M., Notarnicola, M., 2016. Characteristics and Adsorption Capacities of Low-Cost Sorbents for Wastewater Treatment: A Review. Sustainable Materials and Technologies, Volume 9, pp. 10-40

Desmiarti, R., Martynis, M., Trianda, Y., Fusheng, L., Viqri, A., Yamada T., 2019. Phenol Adsorption in Water by Granular Activated Carbon from Coconut Shell. International Journal of Technology, Volume 10(8), pp. 1488-1497

Humelnicu, D., Ignat, M., Doroftei, F., 2015. Agricultural By-Products as Low-Cost Sorbents for the Removal of Heavy Metals from Dilute Wastewaters. Environmental Monitoring and Assessment, Volume 187(5), pp. 1-11

Kahraman, S., Dogan, N., Erdemoglu, S., 2008. Use of Various Agricultural Wastes for the Removal of Heavy Metal Ions. International Journal of Environment and Pollution, Volume 34(1-4), pp. 275-284

Kharitonov, A.P., Simbirtseva, A.G., Tkachev, A.G., Blohin, A.N., Dyachkova, T.P., Maksimkin, A.A., Chukov, D.I., 2016. Reinforcement of Bisphenol-F Epoxy Resin Composites with Fluorinated Carbon Nanotubes. Composites Science and Technology, Volume 134, pp. 161-167

Kusrini, E., Utami, C.S., Usman, A., Nasruddin, Tito, K.A., 2018. $\mathrm{CO}_{2}$ Capture using Graphite Waste Composites and Ceria. International Journal of Technology, Volume 9(2), pp. 287-296

Li, F., Xia, Q., Cheng, Q., Huang, M., Liu, Y., 2017. Conductive Cotton Filters for Affordable and 
Efficient Water Purification. Catalysts, Volume 7(10), pp. 1-12

Lysenko, A., 2007. Prospects for Development of Research and Production of Carbon Fiber Sorbents. Fiber Chemistry, Volume 39(2), pp. 93-102

Mostovoy, A.S., Yakovlev, A.V., 2019. Reinforcement of Epoxy Composites with GraphiteGraphene Structures. Scientific Reports, Volume 9(1), pp. 1-9

Mochida, I., Korai, Y., 2000. Studying Properties of Carbon Fibers. Carbon, Volume 38(2), pp. $227-240$

Nasyrov, I.A., Dvoryak, S., Shaikhiev, I.G., 2017. Sorption Properties of Carbon Waste Pyrolysis Product for Biological Wastewater Treatment. Acta Technica CSAV (Ceskoslovensk Akademie Ved), Volume 61, pp. 323-330

Nasyrov, I.A., Mavrin, G.V, Shaikhiev, I.G., Terentyeva, V.V., 2019. Effect of Ultrasonic Treatment on the Sorption Properties of the Pyrolysis Product of Sludge. IOP Conference Series: Earth and Environmental Science, Volume 288, pp. 1-7

Olufemi, B., Eniodunmo, O., 2018. Adsorption of Nickel(II) Ions from Aqueous Solution using Banana Peel and Coconut Shell. International Journal of Technology, Volume 9(3), pp. 434-445

Perederii, M.A., Kurakov, Y.I., Malikov, I.N., Molchanov, S.V., 2009. Sorption of Petroleum Products by Carbon Sorbents. Solid Fuel Chemistry, Volume 43(5), pp. 302-305

Politaeva, N., Bazarnova, Y., Smyatskaya, Y., Slugin, V., Prokhorov, V., 2017a. Impact of Carbon Dopants on Sorption Properties of Chitosan-Based Materials. Journal of Industrial Pollution Control, Volume 33(2), pp. 1617-1621

Politaeva N.A. Shaikhiev I.G., Slugin V.V., Prokhorov V.V., 2017b. Sorption Properties of Materials Based on Chitosan and Carbon Additives. Technological University Bulletin, Volume 20(23), pp. 100-104

Rozaini, M.N.H., Saad, B., Ramachandran, M.R., Kadir, E.A., 2019. Advanced Materials as Adsorbents in Microextractions for the Determination of Contaminants: A Mini Review. International Journal of Technology, Volume 10(6), pp. 1157-1165

Shaikhiev, I.G., Trushkov, S.M., Kondalenko, O.A., 2010. Waste from Processing Agricultural Crops as Sorbents for Removing Oil Films from Water Surface. Exposition Oil \& Gas, Volume 5, pp. 46-50

Shaikhiev, I.G., 2017. Wool and Waste of Its Processing as Sorption Materials. Bulletin of the Technological University, Volume 20(21), pp. 139-151

Sirotkina, E.E., Novoselova, L., 2005. Materials for Adsorption Purification of Water from Petroleum and Oil Products. Chemistry for Sustainable Development, Volume 13, 359375

Sobgaida, N.A., Ol'shanskaya, L.N., Makarova, Y.A. 2010. Removing Heavy-Metal Ions from Effluents by Means of Sorbent Formed from Wood-Working and Agribusiness Wastes. Chemical and Petroleum Engineering, Volume 45(9), pp. 580-584

Sobgaida, N., Ol'shanskaya, L., Nikitina, I., 2008. Fiber and Carbon Materials for Removing Oil Products from Effluent. Chemical and Petroleum Engineering, Volume 44, pp. 41-44

Svyatchenko, A. V., Sverguzova, S. V., Sapronova, Z. A., Shaikhiev, I. G., 2020. Using Chestnut Leaf Litter in Aqueous Media Purification from Diesel Fuel. Ecology and Industry of Russia, Volume 24(8), pp. 46-50 